\title{
Effects of Quality and Quantity of Information Processing on Design Coordination Performance
}

\author{
R. Zhang1*, A. M. M. Liu², I. Y. S. Chan² \\ ${ }^{1}$ Department of Quantity Survey, School of Construction Management and Real Estate, Chongqing University, Chongqing, China \\ ${ }^{2}$ Department of Real Estate and Construction, Faculty of Architecture, The University of Hong Kong, Hong Kong, China \\ Email: *zhang.rong@cqu.edu.cn
}

How to cite this paper: Zhang, R., Liu, A.M.M. and Chan, I.Y.S. (2018) Effects of Quality and Quantity of Information Processing on Design Coordination Performance. World Journal of Engineering and Technology, 6, 41-49.

https://doi.org/10.4236/wjet.2018.62B005

Received: March 21, 2018

Accepted: May 19, 2018

Published: May 22, 2018

\begin{abstract}
It is acknowledged that lacking of interdisciplinary communication amongst designers can result in poor coordination performance in building design. Viewing communication as information processing activity, this paper aims to explore the relationship between inter-disciplinary information processing (IP) and design coordination performance. Both amount and quality are concerned regarding information processing. 698 project based samples are collected by questionnaire survey from design institutes in mainland China. Statistical data analysis shows that the relationship between information processing amount and design coordination performance follows a nonlinear exponential expression: performance $=3.691\left(1-0.235^{\mathrm{IP} \text { amount }}\right)$ rather than reverted $U$ curve. It implies that design period is too short to allow information overload. It indicates that the main problem in interdisciplinary communication in design institute in China is insufficient information. In additional, it is found the correlation between IP quality and coordination process performance is much stronger than that between IP amount and coordination process performance. For practitioners, it reminds design mangers to pay more attention to information processing quality rather than amount.
\end{abstract}

\section{Keywords}

Inter-Disciplinary, Information Processing, Design Coordination Performance

\section{Introduction}

Changes in construction projects are very common and could lead to project delays and cost overruns. Lu and Issa believe that the most frequent and most 
costly changes are often related to design, such as design changes and design errors [1]. Hence, design stage is of primary importance in construction project life-cycle [2]. Common types of design deficiencies include design information inconsistency (e.g. location of a specific wall differing on the architectural and structural drawings), mismatches/physical interference between connected components (e.g. duct dimensions in building service drawings not matching related pass/hole dimensions in structural drawings), and component malfunctions (e.g. designing a room's electrical supply to suit classroom activities, while architectural drawings designate the room as a computer lab) [3] [4]. Based on a questionnaire survey of 12 leading Canadian design firms, Hegazy, Khalifa and Zaneldin report eight common problems-all of which are due to insufficient and inadequate communication and information exchange (e.g., delay in obtaining information, not everyone on the team getting design change information) [5]. Communication and information exchange is termed information processing in this paper. Information processing includes the collection, processing and distribution of information [6], and can be either personal or impersonal (e.g. accomplished using a program) [7] [8].

Building design is a multi-disciplinary task. The process of designing a building is the process of integrating information from multiple disciplinary professionals (e.g. architects, structure engineers, building service engineers, surveyors). Compared to intra-disciplinary coordination, inter-disciplinary coordination is much more challenging. Information processing in the latter situation might come across knowledge boundary, geographical remoteness, goal heterogeneity, as well as organization boundary (in most of western project design team). In Mainland China, most of time, all disciplinary team are employed in the same design institute. Hence, this paper does not consider the effect of organization boundary in the context of Mainland China.It is acknowledged that lacking of interdisciplinary information processing amongst designers can result in poor design coordination performance (e.g. suboptimal solutions, design change, construction delay).

\section{Information Processing Amount and Design Coordination Performance}

Although there is a number of studies showing that an increase in communication or a shift in the nature of information communicated is related to good performance in high workload situations [9], it is incorrect to posit a linear positive relationship between information processing amount and performance, as too much information processing leads to information overload. Unrestricted communication can also detract from project efficiency and effectiveness [10]. It is well-acknowledged that too little information processing will result in poor performance (e.g. problems in new project development, project failures), as it cannot supply necessary information [11]. However, too much information exchange may allow good performance, but low effectiveness and, even worse, may 
tax performance due to information overload [12] [13]. Redundant information processing overloads people's cognitive capacity, which impedes the normal processing of necessary information. Processing more information than necessary may help to ensure good quality, but it does so at the cost of reduced effectiveness. Coordination and information processing impose additional task loads on project team actors, and should be kept to the minimum necessary to achieve integration. In theory, the relationship between information processing amount and design coordination performance follows a reverted $U$ curve. Due to tight design schedule, the situation in most of design institutes are lacking interdisciplinary communication. The overloaded communication is quite few.

Hence, it is hypothesized that:

The relationship between information processing amount and design coordination performance follows a nonlinear exponential expressione of:

$$
\text { Performance }=b 1\left(1-b 2^{x}\right)
$$

What is the relationship between information processing amount and information processing quality? According to Chinese philosophy, the accumulation of amount increase brings the improvement of quality. Under the context of interdisciplinary information processing in Chinese design institute, it is hypothesized that: The relationship between information processing amount and perceived information quality follows a nonlinear exponential expression of Performance $=b 1\left(1-b 2^{x}\right)$

Literature in the field of communication studies is reviewed here to investigate the concept of information processing quality, for two reasons. The first is that information process quality should be constructed as a multi-dimensional construct to properly investigate its rich content; however, little research within the information processing theory literature discusses the multiple dimensions of information processing quality, perhaps due to the short history of information processing theory. Fortunately, in the communication study community, researchers have deeply discussed the content of information quality in communication [14] [15]. Usually, communication refers to communication between people; here, communication is not limited to people talking to other people directly, but also includes people getting information from media sources, such as online management systems on which other people have posted information. Information processing in design coordination includes both personal communication, and communication through programming; in this sense, communication and information processing are the same issue, which is the second reason why research findings from the communication studies field can be used.

Perceived information quality (PIQ) is a concept applied, in communication literature, to measure information processing quality, and refers to the extent to which an individual perceives information received from a sender as being valuable. At the cognitive level, people choose sources that are perceived to have a greater probability of providing information that will be relevant, reliable, and helpful to the problem at hand-attributes that may be summarize under the la- 
bel perceived source quality [16]. A substantial body of literature suggests that a receiver's perceptions of information quality influences the degree to which he or she is willing to act on it. Six critical communication variables are identified by Thomas et al. [15], four of which are highly related to information processing quality: clarity (how clear the information received is, as indicated by the frequency of conflicting instructions, poor communications, and lack of coordination); understanding (shared with supervisors and other groups) of information expectations; timeliness (of the information received, including design and schedule changes); and, completeness (the amount of relevant information received). Four similar variables are used by Maltz [14], in discussing perceived information quality: credibility (the degree to which information is perceived by the receiver to be a reliable refection of the truth); comprehensibility (perceived clarity of the information received); relevance (the degree to which information is deemed appropriate for the user's task or application); and timeliness (whether information is transmitted quickly enough to be utilized). In a study of coordination quality in construction management, Chang and Shen [17] used two dimensions: perceived utility (i.e., the relevance, credibility and completeness of information) and clarity of communication (i.e., comprehensibility, conciseness, and consistency of representation). The two concepts seem of have some overlap.

In this study, accuracy, relevance, understanding and timeliness have been selected to represent the multi-dimensional construct, PIQ, as shown in Table 1. Accuracy herein refers to the degree to which information is perceived by the receiver to be a reliable refection of the real situation. Relevance denotes the degree to which the information is appropriate for the user's task. Understanding refers to the perceived clarity of the information received. Timeliness represents whether the information is transmitted quickly enough to allow the receiver to complete the task on time.

\section{Methods}

\subsection{Data Collection Method}

Web-based questionnaire survey is applied to collect data for this investigation.

Table 1. Measurement scale of perceived information quality.

The information sent by them is accurate.
They sent me conflicting information. (R)
They communicated important details of design information.
They provided information necessary in design decision making.
It is easy to follow their logic.
Their terminology and concepts are easy to understand.
They presented their ideas clearly.
They provided information in a timely manner.
Their information on design change is too late.
They gave me information that are "old hat".


The target respondents in this survey are participants in a building design project team from a design institute in Mainland China. Respondents are chosen based on three criteria; specifically, respondents should: 1) have participated in a project that had been completed within the past year (as they would be asked to recall design coordination activity); 2) have been either a project design manager, discipline leader, or designer/engineer (top managers is excluded); and 3) have been in one of the following disciplines during the project - project management, architecture, structure engineering, mechanical engineering, electrical engineering, plumbing engineering, or BIM engineering.

1174 questionnaire responses are received, of which 219 are completely ansared, yielding a completion rate of $18.7 \%$. 10 of completely questionnaires are dropped in data analysis as obvious data outliers. Each respondent reported data on his/her dyadic interdisciplinary design coordination with from two to seven disciplines (see Table 2). As the level of analysis is dyadic interdisciplinary design coordination, each questionnaire is split into two to seven samples. Data on both intra- and inter-discipline coordination are collected, although the study's focus is on inter-discipline coordination. The total sample size in the inter-disciplinary coordination data set is 698 (sum of figures in grey background).

\subsection{Measurement}

\subsubsection{Interdisciplinary Communication Amount}

Interdisciplinary communication frequency is applied to measure Interdisciplinary communication amount, using a five-point scale. Respondents are asked to indicate the frequency with which they communicated with designers from other discipline teams $(1=$ zero, $2=$ less than once monthly, $3=$ several times monthly, 4 = several times weekly, 5 = several times daily). Generally, building design has three stages: conceptual design, preliminary design, and detailed design. In each of the different stages, information exchange frequency differs. The conceptual design stage is dominated by architects, with the exception of limited advice-seeking from other disciplines. The most frequent information exchange

Table 2. Matrix of dyadic coordination samples.

\begin{tabular}{cccccccc}
\hline & GD & Archi. & SE & ME & EE & PE & BIM \\
\hline GD & 2 & 5 & 5 & 2 & 2 & 2 & 2 \\
Archi. & 15 & 65 & 65 & 44 & 44 & 44 & 44 \\
SE & 12 & 66 & 66 & 38 & 38 & 38 & 38 \\
ME & 2 & 15 & 15 & 6 & 6 & 6 & 6 \\
EE & 1 & 12 & 12 & 2 & 2 & 2 & 2 \\
PE & 2 & 11 & 11 & 7 & 7 & 7 & 7 \\
BIM & 3 & 19 & 19 & 9 & 9 & 9 & 9 \\
\hline
\end{tabular}

Notes: GD: General Drawing; Archi.: Architecture; SE: Structure Engineering; ME: Mechanical Engineering; EE: Electrical Engineering; PE: Plumping Engineering; BIM: Building Information Modelling. 
happens in the detailed design stage, where all disciplines are heavily involved, with each producing detailed designs to ensure the final product can function well. Hence, frequency of interdisciplinary communication in the detailed design stage is used to test hypotheses in this study.

\subsubsection{Coordination Performance}

Coordination process performance refers to the extent to which the respondent (focal unit a) has effective information processing with another person in the design team (unit $\mathrm{j}$ ). It is a dyadic concept, and the five-item dyadic coordination performance scale used by Sherman and Keller [18] is applied. The scale includes items examining: 1) the extent to which the focal unit a had an effective working relationship with unit $j ; 2$ ) the extent to which unit $j$ fulfilled its responsibilities to unit a; 3) the extent to which unit a fulfilled its responsibilities to unit $\mathrm{j}$; 4) the extent to which the coordination is satisfactory; and, 5) the positive or negative effect on productivity, as a result of the coordination.

\section{Data Analysis}

\subsection{Information Processing Amount and Design Coordination Performance}

For coordination process performance (Table 3), b1 and b2 are quite significant in Model 1. This suggests that the relationship between frequency of interdisciplinary communication in the detailed design stage and coordination process performance can be expressed as:

$$
\text { Performance }=3.691\left(1-0.235^{x}\right)
$$

$\mathrm{H} 1$ is thus strongly supported. In Models 2, 3 and 4, b2 is not significant. One possible reason is that, many other factors influence design project performance, besides coordination process performance.

Table 3. Information processing amount and design coordination performance.

\begin{tabular}{|c|c|c|c|c|}
\hline & Model 1 & Model 2 & Model 3 & Model 4 \\
\hline $\begin{array}{c}\text { Dependent } \\
\text { variable }\end{array}$ & $\begin{array}{l}\text { Coordination } \\
\text { process } \\
\text { performance }\end{array}$ & Design quality & Design schedule & $\begin{array}{c}\text { Design cost } \\
\text { control }\end{array}$ \\
\hline $\begin{array}{c}\text { Independent } \\
\text { variable }\end{array}$ & $\begin{array}{c}\text { Frequency of } \\
\text { interdisciplinary } \\
\text { communication }\end{array}$ & $\begin{array}{c}\text { Frequency of } \\
\text { interdisciplinary } \\
\text { communication }\end{array}$ & $\begin{array}{c}\text { Frequency of } \\
\text { interdisciplinary } \\
\text { communication }\end{array}$ & $\begin{array}{c}\text { Frequency of } \\
\text { interdisciplinary } \\
\text { communication }\end{array}$ \\
\hline \multirow[t]{2}{*}{ b1 } & $3.691^{\star * *}$ & $3.745^{\star \star \star}$ & $3.626^{\star * *}$ & $3.539^{\star * *}$ \\
\hline & $(0.0571)$ & $(0.0472)$ & $(0.0468)$ & $(0.0472)$ \\
\hline \multirow[t]{2}{*}{ b2 } & $0.235^{\star * *}$ & 0.0133 & -0.00138 & -0.0509 \\
\hline & $(0.0448)$ & $(0.0603)$ & $(0.0618)$ & $(0.0630)$ \\
\hline $\mathrm{N}$ & 642 & 445 & 445 & 444 \\
\hline $\begin{array}{c}\text { Adjusted } \\
\text { R-squared }\end{array}$ & 0.904 & 0.937 & 0.934 & 0.928 \\
\hline
\end{tabular}

Standard errors in parentheses ${ }^{*} \mathrm{p}<0.05,{ }^{* *} \mathrm{p}<0.01,{ }^{* *} \mathrm{p}<0.001$; Difference on sample size due to missing data. 


\subsection{Information Processing Amount and Information Processing Quality}

As for the relationship between information processing (IP) amount and information processing quality, the nonlinear exponential expression of Performance $=b 1\left(1-b 2^{x}\right)$ is computed, as shown in Table 4 . Both $b 1$ and $b 2$ are significant. IP quality $=3.353\left(1-0.311^{\mathrm{IP} \text { amount }}\right)$. H2 is strongly supported.

With the assumption that both information processing amount and information processing quality is positively related with design coordination process performance, an explorative study is conducted to compare the correlation using regression function. The results are showed in Table 5.

As it is an explorative study, $\mathrm{P}$ value less than 0.1 is accepted as significant.

The results show that 1 ) Both IP amount and IP quality are positively related with coordination process performance; 2) In addition, it is found the correlation between IP quality and coordination process performance is much stronger than that between IP amount and coordination process performance.

\section{Discussion}

On one hand, insufficient interdisciplinary communication will lead to coordination failure. On the other hand, too much information processing will lead to information overload as well as coordination cost overrun. The challenge for cross-functional teams is to ensure the level of information exchange amongst team members allows them to optimize their performance [11]. In this study, it

Table 4. Information processing amount and information processing quality.

\begin{tabular}{cc}
\hline Dependent variable & Perceived information quality \\
\hline Independent variable & Frequency of interdisciplinary communication \\
& $3.353^{* * *}$ \\
& $(0.0530)$ \\
b2 & $0.311^{\star * *}$ \\
& $(0.0371)$ \\
$\mathrm{N}$ & 852 \\
Adjusted R-squared & 0.892 \\
\hline
\end{tabular}

Standard errors in parentheses ${ }^{*} \mathrm{p}<0.05,{ }^{* *} \mathrm{p}<0.01,{ }^{* *} \mathrm{p}<0.001$; Difference on sample size due to missing data.

Table 5. Information processing amount, information processing quality and coordination process performance.

\begin{tabular}{cccccccc}
\hline & Path & Beta & Std.Err. & $\mathrm{z}$ & $\mathrm{P}>\mathrm{z}$ & \multicolumn{2}{c}{ 90\% Conf. Interval } \\
\hline designer & $\mathrm{cp}<-$ iefd & 0.136 & 0.071 & 1.930 & 0.054 & -0.002 & 0.275 \\
disciplinary leader & $\mathrm{cp}<-$ iefd & 0.128 & 0.042 & 3.070 & 0.002 & 0.046 & 0.210 \\
designer & $\mathrm{cp}<-$ PIQ & 0.614 & 0.046 & 13.23 & 0.000 & 0.523 & 0.705 \\
disciplinary leader & $\mathrm{cp}<-$ PIQ & 0.748 & 0.027 & 27.89 & 0.000 & 0.695 & 0.800 \\
\hline
\end{tabular}


is found that information processing amount is positively related to coordination process performance; specifically, it is found that the relationship between the frequency of interdisciplinary communication in the detailed design stage and coordination process performance followed the nonlinear exponential expression of performance $=3.691\left(1-0.235^{\text {IP amount }}\right)$. Whether the finding can be used in other areas rather than Mainland China need further study.

Although both IP amount and IP quality are positively related with coordination process performance, the correlation between IP quality and coordination process performance is much stronger than that between IP amount and coordination process performance. The result is consistent with former research on decision effectiveness, in which the impact of information quality is stronger [19]. It suggests that more attention should be paid on improving information processing quality. To improve information processing quality, effort can be made on improving information accuracy, relevance, understanding and timeliness. The role of building information modelling in improving interdisciplinary communication could be investigated in the future.

\section{Conclusion}

This paper explores the relationship between interdisciplinary communication and design coordination performance in design institutes in Mainland China. From information processing perspective, interdisciplinary communication is viewed as information processing activity. Both information processing amount and quality are concerned. Information processing quality is measured by four dimensions: perceived information accuracy, relevance, understanding and timeliness. Based on 698 samples of quantitative survey data in project level, it is found that the relationship between information processing amount and design coordination process performance follows a nonlinear exponential expression: performance $=3.691\left(1-0.235^{\text {IP amount }}\right)$ rather than reverted $U$ curve. It implies that design period is too short to allow information overload. It indicates that the main problem in interdisciplinary communication in design institute in China is insufficient information. In additional, it is found the correlation between IP quality and coordination process performance is much stronger than that between IP amount and coordination process performance. For practitioners, it reminds design mangers to pay more attention to information processing quality rather than amount.

\section{References}

[1] Lu, H. and Issa, R.R. (2005) Extended Production Integration for Construction: A Loosely Coupled Project Model for Building Construction. Journal of Computing in Civil Engineering, 19, 58-68. https://doi.org/10.1061/(ASCE)0887-3801(2005)19:1(58)

[2] Harpum, P. (Ed.) (2004) Design Management. John Wiley and Sons Ltd., USA. https://doi.org/10.1002/9780470172391.ch18

[3] Korman, T., Fischer, M. and Tatum, C. (2003) Knowledge and Reasoning for MEP 
Coordination. Journal of Construction Engineering and Management, 129, 627-634. https://doi.org/doi:10.1061/(ASCE)0733-9364(2003)129:6(627)

[4] Mokhtar, A.H. (2002) Coordinating and Customizing Design Information through the Internet. Engineering Construction and Architectural Management, 9, 222-231. https://doi.org/10.1108/eb021217

[5] Hegazy, T., Khalifa, J. and Zaneldin, E. (1998) Towards Effective Design Coordination: A Questionnaire Survey 1. Canadian Journal of Civil Engineering, 25, 595-603. https://doi.org/10.1139/197-115

[6] Tushman, M.L. and Nadler, D.A. (1978) Information Processing as an Integrating Concept in Organizational Design. Academy of Management Review, 613-624.

[7] Dietrich, P., Kujala, J. and Artto, K. (2013) Inter-Team Coordination Patterns and Outcomes in Multi-Team Projects. Project Management Journal, 44, 6-19. https://doi.org/10.1002/pmj.21377

[8] Van de Ven, A.H., Delbecq, A.L. and Koenig Jr., R. (1976) Determinants of Coordination Modes within Organizations. American Sociological Review, 322-338. https://doi.org/10.2307/2094477

[9] Mathieu, J.E., Heffner, T.S., Goodwin, G.F., Salas, E. and Cannon-Bowers, J.A. (2000) The Influence of Shared Mental Models on Team Process and Performance. Journal of Applied Psychology, 85, 273. https://doi.org/10.1037/0021-9010.85.2.273

[10] Katz, D. and Kahn, R.L. (1978) The Social Psychology of Organizations.

[11] Patrashkova, R.R. and McComb, S.A. (2004) Exploring Why More Communication Is Not Better: Insights from a Computational Model of Cross-Functional Teams. Journal of Engineering and Technology Management, 21, 83-114. https://doi.org/10.1016/j.jengtecman.2003.12.005

[12] Goodman, P.S. and Leyden, D.P. (1991) Familiarity and Group Productivity. Journal of Applied Psychology, 76, 578. https://doi.org/10.1037/0021-9010.76.4.578

[13] Boisot, M.H. (1995) Information Space. Int. Thomson Business Press.

[14] Maltz, E. (2000) Is All Communication Created Equal? An Investigation into the Effects of Communication Mode on Perceived Information Quality. Journal of Product Innovation Management, 17, 110-127. https://doi.org/10.1016/S0737-6782(99)00030-2

[15] Thomas, S.R., Tucker, R.L. and Kelly, W.R. (1998) Critical Communications Variables. Journal of Construction Engineering and Management, 124, 58-66. https://doi.org/10.1061/(ASCE)0733-9364(1998)124:1(58)

[16] Choo, C.W. (2005) The Knowing Organization. Oxford University Press. https://doi.org/10.1093/acprof:oso/9780195176780.001.0001

[17] Chang, A.S. and Shen, F.-Y. (2014) Effectiveness of Coordination Methods in Construction Projects. Journal of Management in Engineering. https://doi.org/10.1061/(ASCE)ME.1943-5479.0000222

[18] Sherman, J.D. and Keller, R.T. (2011) Suboptimal Assessment of Interunit Task Interdependence: Modes of Integration and Information Processing for Coordination Performance. Organization Science, 22, 245-261. https://doi.org/10.1287/orsc.1090.0506

[19] Keller, K.L. and Staelin, R. (1987) Effects of Quality and Quantity of Information on Decision Effectiveness. Journal of Consumer Research, 14, 200-213.

https://doi.org/10.1086/209106 